УДК 331.1

Пильман Кирилл Станиславович, студент 2 курса магистратуры Института экономики и управления ФГБОУ ВО «Курский государственный университет», Россия, г. Курск

e-mail: kirill.pilman@mail.ru

\title{
ОСНОВЫ УПРАВЛЕНИЯ ПЕРСОНАЛОМ
}

Аннотация: в данной статье приведены основы формирования оптимальной системы управления персоналом. Перечислены основные принципы управления, модели и рекомендации, а также дано описание основных стратегий управления.

Ключевые слова: управление персоналом, менеджмент, принципы, цели, задачи, стратегии.

Pilman Kirill, student 2 course of magistracy Institute of economics and management Kursk State University Russia, Kursk

e-mail:kirill.pilman@mail.ru

\section{BASIS OF PERSONNEL MANAGEMENT}

Annotation: this article presents the basics of forming an optimal personnel management system. Lists the basic principles of management, models and recommendations, and also describes the basic management strategies.

Keywords: personnel management, management, principles, goals, objectives, strategies.

Менеджмент - управление персоналом, направленное преимущественно на достижение целей организации, а не работников. Но так как персонал способен принимать решения и оценивать требования, выражать протест в случае несогласия с правилами, система строится на выгодных 
взаимоотношениях, сотрудничестве. От действий менеджера напрямую зависит динамика развития организации, эффективность труда, прибыльность и многое другое. Начинающие руководители часто совершают ошибки, которых можно избежать, если досконально изучить процесс управления персоналом, а на основании теоретической информации разработать собственную стратегию.

В каждой компании правила сотрудничества с подчиненными подбирают индивидуально, поэтому нельзя копировать опыт других, но можно брать его за основу. Следует придерживаться базовых принципов, которые дополняйте нормами, помогающими достичь желаемой цели и держать под контролем бизнес-процессы.

Основные принципы и задачи управления представлены схематично на рисунке 1 [3, с. 48-52].

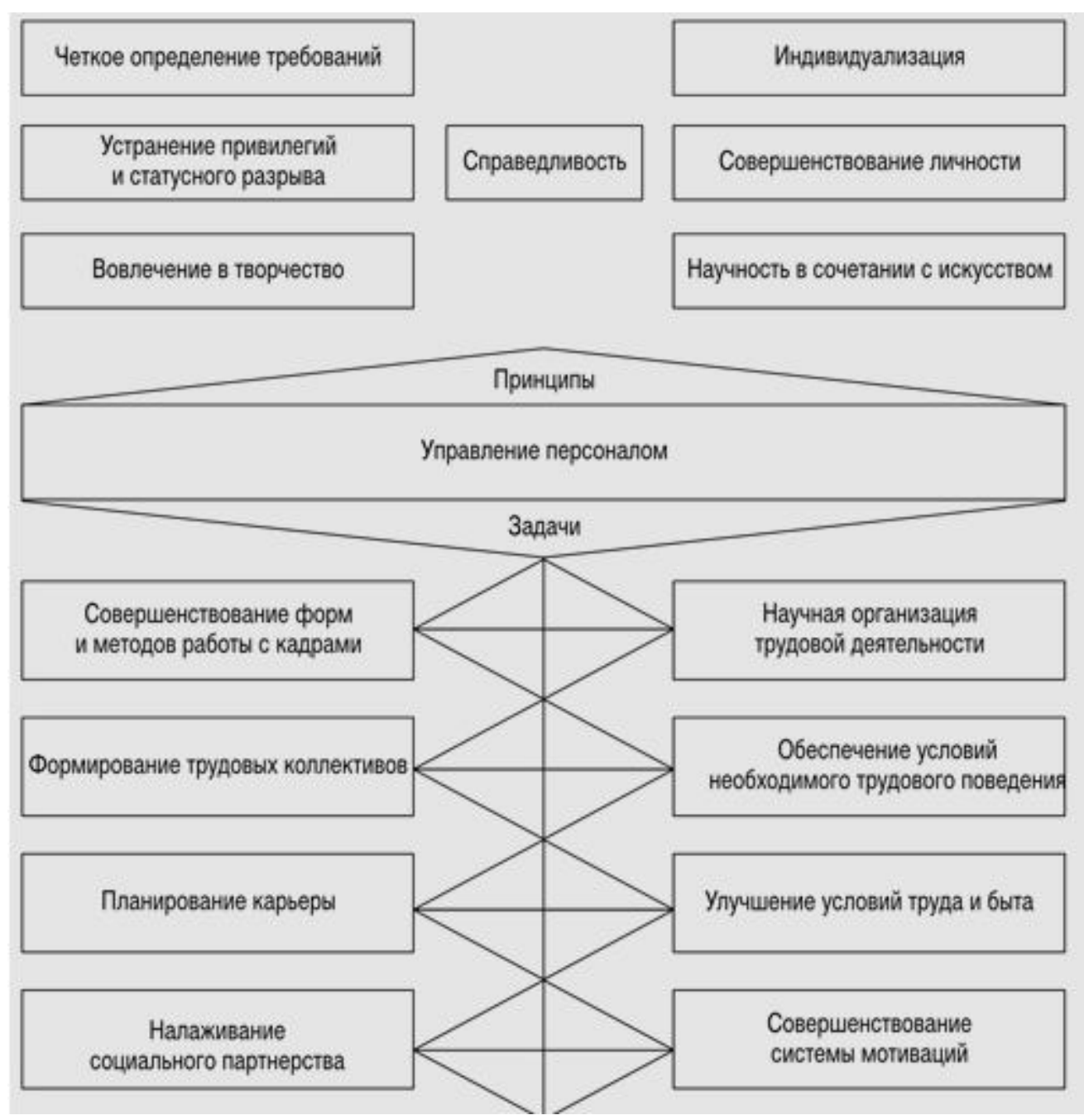

Рисунок 1 - Основные принципы и задачи управления персоналом

Перечислим принципы, которых стоит придерживаться руководителям в процессе управления: 
- подбирайте персонал по личным, профессиональным и деловым качествам;

- соблюдайте преемственность - сочетайте в коллективе молодых и опытных работников;

- обеспечивайте карьерный рост специалистов, своевременно перемещайте лучших сотрудников, которые стабильно показывают высокие результаты;

- поддерживайте дух соревнований, ведь он позволяет раскрываться потенциалу человека;

- доверяйте работникам, но проверяйте их исполнительность; практикуйте автоматическое замещение отсутствующих сотрудников другими специалистами, которые способны справляться с должностными обязанностями;

- отправляйте работников на обучение, чтобы уровень квалификации кадров был на должном уровне;

- принимайте решения на основе правовых актов [3, с. 48-52].

Чтобы повысить эффективность работы с персоналом, исключить ненужную бумажную работу, сократить количество ошибок в документах, можно автоматизировать процессы управления персоналом с помощью специальных программных продуктов, таких как Фараон, 1С: Зарплата и управление персоналом, Assessment Tools и др. Они позволяют автоматизировать кадровый документооборот, осуществлять прием на работу, перевод, оформление больничных, отпусков, ведение личных карточек и многое другое.

Для верного управления необходимо сочетать разные методы между собой, искать баланс. Так следует применять административные, экономические и социально-психологические способы влияния на сотрудников. Побуждать коллектив соблюдать трудовую дисциплину, придерживаться установленных правил. Регламентировать нормы и знакомить с ними сотрудников. Важно также следить за тем, чтобы в коллективе не было негласных правил, продвигаемых лидерами. Они могут противоречить утвержденным нормам, негативно влиять на процессы, коллектив, 
психологический климат, имидж организации и т.д. Следует мотивировать с помощью экономических методов, но также необходимо учитывать, что эти меры имеют влияние не на всех сотрудников. Для многих важно признание, поэтому следует уделять внимание и социальным механизмам воздействия. Необходимо создавать благоприятные условия работы, устранять напряженность, показывать значимость каждого работника.

Стратегии - главные направления при создании актуальной системы менеджмента. С помощью них формируется сплоченный, профессиональный и конкурентоспособный кадровый состав организации. Стратегия управления тесно связывается с общей концепцией развития, отличается долгосрочностью.

Выделяют 5 типов стратегии управления персоналом. При выборе стратегии следует учитывать экономическую ситуацию в компании, особенности кадрового состава, возможность карьерного роста и развития, требования к сотрудникам и уровню профессиональной подготовки.

В таблице 1 представим основные типы стратегий и их описание [2, с. 112-118].

Таблица 1 - Типы стратегий управления персоналом

\begin{tabular}{|c|c|}
\hline Название стратегии & Описание \\
\hline 1 & 2 \\
\hline $\begin{array}{c}\text { Предпринимательская } \\
\text { стратегия }\end{array}$ & $\begin{array}{c}\text { Стратегия характерна для организаций, которые занимаются } \\
\text { новым видом деятельности. В центре их внимания - } \\
\text { удовлетворение требований заказчика. Такая тактика отличается } \\
\text { характерными чертами: отбор сотрудников на долговременную } \\
\text { работу, готовых рисковать, проявлять инициативность; } \\
\text { вознаграждение на конкурентной основе; оценка по реальным } \\
\text { результатам (KРI); ориентация на наставника, неформальное } \\
\text { развитие личности; кадровые перестановки с учетом интересов } \\
\text { персонала. } \\
\end{array}$ \\
\hline $\begin{array}{c}\text { Стратегия } \\
\text { динамического роста }\end{array}$ & $\begin{array}{c}\text { Политика отличается тем, что решения принимаются на основе } \\
\text { сопоставления средств и целей. Она оптимальна в период } \\
\text { заложения фундамента будущего компании. В целом стратегия } \\
\text { динамического роста имеет следующие особенности: отбор, } \\
\text { расстановка кадров нацелены на поиск гибких и лояльных } \\
\text { работников; справедливое вознаграждение с учетом заслуг } \\
\text { (премии); оценка кадров ведется по четко оговоренным критериям; } \\
\text { акцент на развитии личности; планирование перестановок с учетом } \\
\text { возможностей организации. }\end{array}$ \\
\hline $\begin{array}{c}\text { Стратегия } \\
\text { прибыльности }\end{array}$ & $\begin{array}{c}\text { Стратегия управления персоналом направлена на сохранение } \\
\text { прибыльности предприятия. Она подходит компаниям, которые } \\
\text { добились успеха, заняли одну из лидирующих позиций. Политика } \\
\text { прибыльности имеет ряд характеристик: жесткий отбор и }\end{array}$ \\
\hline
\end{tabular}




\begin{tabular}{|c|c|}
\hline \hline Название стратегии & Описание \\
\hline 1 & 2 \\
\hline \multirow{5}{*}{ Стратегия ликвидации } & расстановка кадров; вознаграждение основывается на заслугах, \\
& старшинстве, справедливости; узкая оценка персонала, \\
& ориентированная на результат; концентрация на развитии для \\
& выполнения поставленных задач; жесткое планирование \\
& перестановок. \\
\hline & Тактику применяют в период кризиса в организации, когда \\
& происходит продажа активов, сокращается штат. Она имеет \\
& уровень оплаты труда не повышается, нет дополнительного \\
& стимулирования; оценка персонала строгая и формальная; нет \\
развитие и обучение; выборочное продвижение сотрудников.
\end{tabular}

Стратегии можно менять, выбирая каждый раз ту, которая больше соответствует реальности. Не следует создавать иллюзию благополучия, если компания находится в сложной ситуации, когда отмечается упадок. От подхода руководства к управлению персоналом напрямую зависит репутация организации, поэтому следует взвешивать все «за»и «против», только затем принимать решения.

\section{Список источников:}

1) Забродин, В. Ю. Социология и психология управления: учебник и практикум для бакалавриата и магистратуры / В. Ю. Забродин. - Москва: Издательство Юрайт, 2019. - 147 с.;

2) Мансуров, Р. Е. Настольная книга директора по персоналу: практ. пособие / Р. Е. Мансуров. - 2-е изд., перераб. и доп. - Москва: Издательство Юрайт, 2019. — 384 с.;

3) Медведева, Т. А. Основы теории управления: учебник и практикум для академического бакалавриата / Т. А. Медведева. - Москва: Издательство Юрайт, 2019. - 191 с. 